\title{
Inverse perovskite oxysilicides and oxygermanides as candidates for non-toxic infrared semiconductor and their chemical bonding nature
}

Naoki Ohashi ${ }^{1,2, *}$, David Mora-Fonz ${ }^{3}$, Shigeki Otani ${ }^{1}$, Takeshi Ohgaki ${ }^{1}$, Masashi Miyakawa ${ }^{1}$, and Alexander Shluger ${ }^{3}$

1 National Institute for Materials Science (NIMS), Namiki, Tsukuba, Ibaraki 305-0044, Japan

2 Materials Center for Elemental Strategy (MCES), Tokyo Institute of Technology (Tokyo Tech), Nagatsuta, Midori-ku, Yokohama, Japan.

3 Department of Physics and Astronomy, University College London, Gower Street, London WC1E 6BT, United Kingdom.

* Corresponding Author: OHASHI.Naoki@nims.go.jp

\begin{abstract}
We have synthesized inverse-perovskite-type oxysilicides and oxygermanides represented by $R_{3} \mathrm{SiO}$ and $R_{3} \mathrm{GeO}(R=\mathrm{Ca}$ and $\mathrm{Sr})$ and studied theircharacteristics in search for non-toxic narrow band gap semiconductors. These compounds exhibit a sharp absorption edge around $0.9 \mathrm{eV}$ and a luminescence peak in the same energy range. These results indicate that the obtained materials have direct-band electronic structure, which was confirmed by hybrid DFT calculations. These materials, made from earth abundant and non-toxic elements and with relatively light electron/hole effective mass, represent strong candidates for non-toxic optoelectronic devices in the infrared range.
\end{abstract}


Inverse perovskite for infrared optics by N. Ohashi et al.

\section{Introduction}

Optoelectronic devices, particularly in the infrared (IR) range, have many important applications, such as sensors and emitters in optical fiber communication..$^{1,2}$ IR sensors are used, for example, in self-driving vehicles to achieve night time view. ${ }^{3}$ However, most of conventional semiconductors used in IR optics contain toxic elements, with the most typical example being mercury—cadmium—telluride (MCT). ${ }^{4}$ Optical sensors utilizing MCT exhibit high sensitivity in IR range, but all constituting elements, mercury $(\mathrm{Hg}),{ }^{5}$ cadmium $(\mathrm{Cd}),{ }^{6,7}$ and tellurium $(\mathrm{Te})^{8}$ are toxic and irreplaceable in the current semiconductor technology based on concepts used to develop II-VI and III-V semiconductors.

In particular, over severaldecades, the strategy for band-gap $\left(E_{g}\right)$ engineering in semiconductor development has been driven by elemental substitution in so called II-VI or III-V systems. ${ }^{9-12}$ This strategy is based on the observation that the band gap energy tends to be narrowed by adding elements with a large atomic number. The latter is one of the main reasons why MCT have been adopted for optoelectronic devices used in IR ranges. Following this strategy, it is impossible to obtain narrow band gap materials without employing heavy elements in II-VI and III-V semiconductors. One of the directions to reduce the number of toxic elements used in those semiconductors, is cation substitution. For instance, combining the I and III group elements for substitution of the group II elements, such as a combination of $(\mathrm{Cu}, \mathrm{Ga})$ and $(\mathrm{Cu}, \mathrm{In})$ for substitution of $\mathrm{Cd}$, is one of the ways of toxicity reduction. ${ }^{12-15}$ Toxic anions from the V and VI-group are, however, still necessary to form (I,III)- VI semiconductors. Hence, it is paramount to find appropriate anions to formcompounds to overcome this limitation.

In this regard, silicides, germanides, and stannites, using group IV-elements as a tetravalent anion in a formal charge state, have recently attracted interest in search for non-toxic semiconductors. One such example is magnesium silicide $\left(\mathrm{Mg}_{2} \mathrm{Si}\right){ }^{16-21}$ which is formed by using silicon as a tetravalent anion. However, the $\mathrm{Mg}_{2} \mathrm{Si}$ band structure is of indirect-transition-type and, hence, it cannot be useful as a light emitter. ${ }^{22,23}$ In contrast, there are some silicide semiconductors with direct-transition-type band structure, such as $\mathrm{Sr}_{2} \mathrm{Si}$ and $\mathrm{Ba}_{2} \mathrm{Si}_{2}{ }^{24}$ but, to the best of our knowledge, their luminescence properties have not yet been reported. For applications in optoelectronics, particularly light emitting devices, it is essential to find semiconductors which exhibit the required luminescence properties.

Recently, the utilization of photonic structures has been proposed as a way to overcome the difficulty in 
Inverse perovskite for infrared optics by N. Ohashi et al.

fabricating non-toxic optoelectronic devices in the IR range. For instance, plasmonic structures composed ofgold thin film have been used to enhance IR emission ${ }^{25}$ and detection. ${ }^{26}$ The efficiency of IR detection as high as characteristic to MCT-based devices has been achieved with GaAs-based devices combined with a photonic structure composed of gold. Other prospective $R_{3} M O$ [ $R=($ alkali earth elements) and $M=$ (group IV elements)] compounds are attracting interest in terms of electron transport properties. Very recently, their thermoelectric properties have been studied in ref. ${ }^{27}$ Particularly, it has been reported that non-stoichiometric strontiumstannite $\left[\mathrm{Sr}_{3-\mathrm{x}} \mathrm{SnO}(R=\mathrm{Sr}\right.$ and $\left.M=\mathrm{Sn})\right]$ exhibits topological superconductivity. ${ }^{28}$ These materials can become good candidates for non-toxic IR semiconductors with photonic structures for high efficiency devices in the IR range.

In this paper, we explore severalnew $R_{3} M O$ compound semiconductors with relatively narrow direct optical band gap. It has been reported that $R_{3} M O$ compounds possess the inverse-perovskite-type crystal structure with corner-sharing $\left[\mathrm{O}_{6}\right]$ octahedron units. ${ }^{29-31}$ Formal charges of $M, R$ and $\mathrm{O}$ are expected to be $-4 e,+2 e$ and $-2 e$, respectively. Because we are particularly interested in non-toxic materials with semiconducting properties, in this work we focused on $R_{3} M O$ compounds with relatively light elements, which include synthesis and characterization of oxysilicides and oxygermanides. The energy band structures of these compounds were calculated using hybrid density functional theory (h-DFT) and their optical properties were analyzed by optical absorption and luminescence spectroscopy. Our results confirm that these $R_{3} M O$ materials have direct-transitiontype band structure and their band gap energy is less than $1 \mathrm{eV}$. Therefore we suggest that the oxysilicides $\left(\mathrm{Ca}_{3} \mathrm{SiO}\right.$, $\left.\mathrm{Sr}_{3} \mathrm{SiO}\right)$, oxygermanides $\left(\mathrm{Ca}_{3} \mathrm{GeO}, \mathrm{Sr}_{3} \mathrm{GeO}\right)$ and their solid solutions, are strong candidates for optoelectronic applications, including light emitters.

\section{Experiments}

The inverse-perovskite-type $R_{3} M \mathrm{O}$ compounds, oxysilicides $(M=\mathrm{Si})$ and oxygermanides $(M=\mathrm{Ge})$ with $R=\mathrm{Mg}$, $\mathrm{Ca}$ and $\mathrm{Sr}$ and their solid solution compounds, were synthesized by solid-state reactions. Selected source materials were pure elemental compounds, such as $\mathrm{Mg}, \mathrm{Ca}, \mathrm{Sr}$, $\mathrm{Si}$ and $\mathrm{Ge}$ and dioxides $\mathrm{SiO}_{2}$ and $\mathrm{GeO}_{2}$. Oxides were used as both the source of oxygen and $M$-elements. The source materials were weighed to satisfy the atomic ratio of $R: M: \mathrm{O}=3: 1: 1$ and sealed in a tube made from pure metallic tantalum $(\mathrm{Ta})$. The sealed precursors were heated in pure $\mathrm{Ar}$ atmosphere at $900-1050^{\circ} \mathrm{C}$ for $24-45 \mathrm{~h}$ to induce formation of $R_{3} M \mathrm{O}$ compounds. The 
Inverse perovskite for infrared optics by N. Ohashi et al.

reaction products were stored in glass cylinder filled with liquid paraffin to prevent oxidation of the samples with air. The obtained samples were characterized by X-ray powder diffraction (XRD) for phase identification. The samples were covered with liquid paraffin to avoid oxidation during measurements.

Optical properties of the products were measured with a conventional UV-VIS-IR spectrometer at room temperature. Here, diffuse reflectance measurement was employed utilizing integration sphere made of $\mathrm{BaSO}_{4}$ for the pelletized samples formed by pressing. The luminescence properties of the samples were also measured at room temperature. A pulsed laser source (wavelength at $800 \mathrm{~nm}$, repetition rate at $82 \mathrm{MHz}$, pulse width at 150 fs and average power at about $50 \mathrm{~mW}$ ) was used for excitation, whereas the luminescence spectra were obtained by an Acton VM-505 monochromator with a Hamamastu G10899-03K InGaAs PIN photodiode detector. For photoluminescence (PL) measurements, the powder samples were fixed on conventional adhesive tape and pure nitrogen gas was flown on sample surface to prevent reaction between the sample and air. Absence of the luminescence peak from the adhesive tape was confirmed.

\section{Computational details}

Electronic structure and lattice parameters of the $R_{3} M \mathrm{O}$ compounds were calculated using the periodic plane wave DFT code VASP (Vienna ab initio Simulation Package) ${ }^{32,33}$ with the projector-augmented wave (PAW) $\operatorname{method}^{34,35}$ for describing interactions between the cores and the valence electrons $(\mathrm{Ca}:[10 e], \mathrm{Si}:[4 e], \mathrm{Sr}:[10 e]$, $\mathrm{Ge}:[14 e], \mathrm{Mg}:[8 e]$ and $\mathrm{O}:[6 e])$ of the involved atoms. The exchange-correlation energy was calculated using two generalized gradient approximation (GGA) functionals: Perdew-Burke-Ernzerhof $(\mathrm{PBE})^{36}$ and the PBE functional revised for solids, PBEsol. ${ }^{37}$ For a more accurate description of electronic structure, the hybrid PBE0 and PBEsol0 functionals ${ }^{38,39}$ were used with a $25 \%$ of the exact exchange.

Calculations were performed by assuming a Pnma symmetry (orthorhombic crystal system) ${ }^{40}$ for every structure, in agreement with previous reports. ${ }^{29,30}$ For the structural optimizations, total energy convergence to less than $1 \mathrm{meV} /$ atom was achieved with respect to the k-point sampling and energy cutoff, keeping the symmetry fixed. A kinetic energy cutoff of $500 \mathrm{eV}$ and a k-point spacing of $0.3 \AA^{-1}$ was used for bulk relaxations, whereas a single point calculation with a k-point spacing of $0.2 \AA^{-1}$ was used for the density of states (DOS). Structural optimization was achieved when the forces on the ions were all less than $0.01 \mathrm{eV} \AA^{-1}$. The stability of the structure 
Inverse perovskite for infrared optics by N. Ohashi et al.

was studied by calculating the enthalpy of formation, which was done by comparing the total energy of the $R_{3} M O$ structures and the compounds used as precursors during the synthesis. The obtained electronic structure was analyzed by calculating the projected density of state (PDOS) and local density of state (LDOS) using k-point sampling on the Monkhorst-Pack grid. ${ }^{41,42}$ The energy-momentum dispersion of electrons (band diagram) was also calculated to evaluate electron and hole effective mass es using the relationship:

$$
\frac{1}{m_{i j}^{*}}=\frac{\partial^{2} E(\mathbf{k})}{\partial k_{i} \partial k_{j}} \frac{1}{\hbar^{2}}
$$

where $E(\mathbf{k})$ is defined as the eigenvalue of the band at a specific k-point, $k_{i}$ and $k_{j}$ are the $i$ th and $j$ th elements of

$\mathbf{k}$, and $m_{i j}^{*}$ as the element of effective mass tensor. The band structure diagrams were plotted using the sumo package ${ }^{43}$ Moreover, the charge distribution in $R_{3} M O$ was quantified using the Bader analys is.${ }^{44}$

As mentioned, we focus on the exploration of different anions. In an attempt to provide a better characterization of the $M^{4-}$ anions, we have considered not only $R_{3} M \mathrm{O}$ but also $R_{2} M$ compounds. For cons istency, both $R_{3} M \mathrm{O}$ and $R_{2} M$ compounds were modelled using the VASP code with the nonlocal PBEsol0 functional. We note that, although there are several prior computational studies of $R_{2} M$ compounds,${ }^{45-48}$ comparison with them is hampered by the different methods/functionals used.

\section{Experimental results}

Table 1 shows the results of our synthesis study. The striking result is that the inverse-perovskite-type $R_{3} M O$ including Mg was not obtained, although the other samples were almost single phase with minor extra phases. As shown in the supporting information (see Fig. S-1), the sample with nominal composition as $\mathrm{Mg}: \mathrm{Si}: \mathrm{O}=3: 1: 1$ was found to be a mixture with no-trace of inverse-perovskite-type structure. We examined the synthesis of $\left(R^{\mathrm{I}}, R^{\mathrm{II}}\right)_{3} M \mathrm{O}$ solid solutions with $R^{1}=\mathrm{Mg}$, but there was no evidence for formation of $\left(\mathrm{Mg}, R^{\mathrm{II}}\right)_{3} M \mathrm{O}$ solid solutions. Indeed, the samples with nominal composition as $\mathrm{Mg}: \mathrm{Ca}: \mathrm{Si}: \mathrm{O}=1.5: 1.5: 1: 1$ were a mixture containing $\mathrm{Ca}_{3} \mathrm{SiO}$ but the lattice parameters of $\mathrm{Ca}_{3} \mathrm{SiO}-$ phase was exactly the same as that of the sample with nominal composition $\mathrm{Ca}: \mathrm{Si} \mathrm{O}=3: 1: 1$. The latter means that $\mathrm{Mg}$ cannot be dis solved into the oxysilicide or oxygermanide compounds with an inverse-perovskite-type structure due to material's instability. We are not aware of published reports on 
Inverse perovskite for infrared optics by N. Ohashi et al.

stable $\mathrm{Mg}_{3} \mathrm{MO}$ compounds with an inverse-perovskite-type phase, which is an important indication when considering the chemical bonding nature in $R_{3} M \mathrm{O}$ compounds.

Table 1 Nominal precursor composition and the obtained compounds identified by X-ray diffraction.

\begin{tabular}{|c|c|c|c|c|c|c|}
\hline \multicolumn{5}{|c|}{ Nominal precurs or composition ratio } & \multicolumn{2}{|r|}{ Reaction products } \\
\hline \multicolumn{2}{|c|}{$M$} & \multicolumn{3}{|c|}{$R$} & \multirow{2}{*}{ Major phase } & \multirow{2}{*}{ Minor phases } \\
\hline Ge & $\mathrm{Si}$ & $\mathrm{Mg}$ & $\mathrm{Ca}$ & $\mathrm{Sr}$ & & \\
\hline 1.0 & 0.0 & 0.0 & 3.0 & 0.0 & $\mathrm{Ca}_{3} \mathrm{GeO}$ & $\mathrm{CaO}, \mathrm{Ca}_{2} \mathrm{Ge}$ \\
\hline 0.0 & 1.0 & 0.0 & 3.0 & 0.0 & $\mathrm{Ca}_{3} \mathrm{SiO}$ & $\mathrm{CaO}, \mathrm{Ca}_{2} \mathrm{Si}$ \\
\hline 0.0 & 1.0 & 0.0 & 0.0 & 3.0 & $\mathrm{Sr}_{3} \mathrm{SiO}$ & $\mathrm{SrO}, \mathrm{Sr}_{2} \mathrm{Si}$ \\
\hline 0.5 & 0.5 & 0.0 & 1.0 & 0.0 & $\mathrm{Ca}_{3}(\mathrm{Si}, \mathrm{Ge}) \mathrm{O}$ & $\mathrm{CaO}, \mathrm{Ca}_{2}(\mathrm{Si}, \mathrm{Ge})$ \\
\hline 0.0 & 1.0 & 1.5 & 1.5 & 0.0 & $\mathrm{Ca}_{3} \mathrm{SiO}$ & $\mathrm{Mg}_{2} \mathrm{Si}, \mathrm{MgO}, \mathrm{CaMg}_{2}, \mathrm{Ca}_{2} \mathrm{Si}, \mathrm{CaO}, \mathrm{Ca}$ \\
\hline 0.0 & 1.0 & 3.0 & 0.0 & 0.0 & $\mathrm{Mg}_{2} \mathrm{Si}, \mathrm{MgO}$ & \\
\hline
\end{tabular}

To justify why our results that $\left(\mathrm{Mg}, R^{\mathrm{II}}\right)_{3} M \mathrm{O}$ solid solutions could not be formed, we discuss the variation of the lattice parameters. As shown in Table 2, the lattice parameters of $R_{3} M O$ compounds are very sensitive to substitution of $R$-elements. Indeed, unit cell volumes of $\mathrm{Ca}_{3} \mathrm{SiO}$ and $\mathrm{Sr}_{3} \mathrm{SiO}$ differ significantly at 0.4192 and $0.5104 \mathrm{pm}^{3}$, respectively. On the other hand, lattice parameters of $R_{3} M \mathrm{O}$ are much less sensitive to substitution of $M$-element. The unit cell volume of $\mathrm{Ca}_{3} \mathrm{GeO}$ is $0.4225 \mathrm{pm}^{3}$ which is only by $0.8 \%$ larger than that of $\mathrm{Ca}_{3} \mathrm{SiO}$. As the lattice parameters are highly sensitive to substitution of $R$-element, we can assume that incorporation of $\mathrm{Mg}$ into $R_{3} M \mathrm{O}$ lattice should result in obvious reduction of lattice parameters in terms of ionic radius. ${ }^{49,50}$ The lattice parameters of $R_{3} M \mathrm{O}$ will be discussed below in greater detail. 
Inverse perovskite for infrared optics by N. Ohashi et al.

Table 2 Experimentally determined or theoretically calculated lattice parameters and electronic characteristics of $R_{3} M \mathrm{O}$. The $E_{g}$ values shown here were experimentally determined by diffuse reflectance measurement or by DFT-calculations with various functionals.

\begin{tabular}{|c|c|c|c|c|c|c|c|}
\hline \multicolumn{3}{|c|}{ Composition } & \multirow{2}{*}{$\begin{array}{c}\text { Method/ } \\
\text { Functional }\end{array}$} & \multicolumn{3}{|c|}{ Lattice parameters } & \multirow{2}{*}{ Characteristics } \\
\hline$R$ & $M$ & Fomula & & $\mathrm{a} / \mathrm{pm}$ & $\mathrm{b} / \mathrm{pm}$ & $\mathrm{c} / \mathrm{pm}$ & \\
\hline \multirow{5}{*}{$\mathrm{Mg}$} & \multirow{5}{*}{$\mathrm{Si}$} & \multirow{5}{*}{$\mathrm{Mg}_{3} \mathrm{SiO}$} & Expt. & \multicolumn{3}{|c|}{ Not obtained } & $\mathrm{N} / \mathrm{A}$ \\
\hline & & & PBE & 0.596 & 0.851 & 0.596 & Metallic \\
\hline & & & PBEsol & 0.592 & 0.844 & 0.592 & Metallic \\
\hline & & & PBEO & 0.591 & 0.843 & 0.591 & Metallic \\
\hline & & & PBEsol0 & 0.588 & 0.839 & 0.588 & Metallic \\
\hline \multirow{13}{*}{$\mathrm{Ca}$} & \multirow{6}{*}{$\mathrm{Si}$} & \multirow{6}{*}{$\mathrm{Ca}_{3} \mathrm{SiO}$} & Expt. & 0.667 & 0.943 & 0.667 & $E_{\mathrm{g}}=0.87(\mathrm{eV})$ \\
\hline & & & Expt.[ref] & 0.668 & 0.943 & 0.667 & $N / A$ \\
\hline & & & PBE & 0.668 & 0.946 & 0.669 & $E_{\mathrm{g}}=0.21(\mathrm{eV})$ \\
\hline & & & PBEs ol & 0.659 & 0.934 & 0.661 & Metallic \\
\hline & & & PBE0 & 0.665 & 0.942 & 0.667 & $\mathrm{Eg}=1.22(\mathrm{eV})$ \\
\hline & & & PBEsol0 & 0.660 & 0.934 & 0.661 & $E_{\mathrm{g}}=1.07(\mathrm{eV})$ \\
\hline & $\mathrm{Si} / \mathrm{Ge}$ & $\mathrm{Ca}_{3}\left(\mathrm{Si}_{0.5} \mathrm{Ge}_{0.5}\right) \mathrm{O}$ & Expt. & 0.668 & 0.944 & 0.668 & $E_{\mathrm{g}}=0.84(\mathrm{eV})$ \\
\hline & \multirow{6}{*}{$\mathrm{Ge}$} & \multirow{6}{*}{$\mathrm{Ca}_{3} \mathrm{GeO}$} & Expt. & 0.669 & 0.945 & 0.669 & $E_{\mathrm{g}}=0.80(\mathrm{eV})$ \\
\hline & & & Expt.[ref] & 0.668 & 0.945 & 0.669 & $N / A$ \\
\hline & & & $\mathrm{PBE}$ & 0.670 & 0.948 & 0.673 & $E_{\mathrm{g}}=0.15(\mathrm{eV})$ \\
\hline & & & PBEs ol & 0.661 & 0.935 & 0.663 & $\mathrm{Eg}=0.05(\mathrm{eV})$ \\
\hline & & & PBE0 & 0.667 & 0.944 & 0.670 & $\mathrm{Eg}=1.23(\mathrm{eV})$ \\
\hline & & & PBEsol0 & 0.661 & 0.935 & 0.663 & $E_{\mathrm{g}}=1.14(\mathrm{eV})$ \\
\hline \multirow{11}{*}{$\mathrm{Sr}$} & \multirow{6}{*}{$\mathrm{Si}$} & \multirow{6}{*}{$\mathrm{Sr}_{3} \mathrm{SiO}$} & Expt. & 0.712 & 1.007 & 0.712 & $E_{\mathrm{g}}=0.84(\mathrm{eV})$ \\
\hline & & & Expt.[ref] & 0.713 & 1.007 & 0.712 & $N / A$ \\
\hline & & & PBE & 0.721 & 1.015 & 0.715 & $N / A$ \\
\hline & & & PBEs ol & 0.708 & 1.001 & 0.706 & 0.24 \\
\hline & & & PBE0 & 0.715 & 1.009 & 0.712 & 1.41 \\
\hline & & & PBEs ol0 & 0.707 & 1.000 & 0.705 & 1.26 \\
\hline & \multirow{5}{*}{$\mathrm{Ge}$} & \multirow{5}{*}{$\mathrm{Sr}_{3} \mathrm{GeO}$} & Expt.[ref] & 0.715 & 1.010 & 0.713 & $N / A$ \\
\hline & & & PBE & 0.723 & 1.019 & 0.718 & $E_{\mathrm{g}}=0.43(\mathrm{eV})$ \\
\hline & & & PBEsol & 0.710 & 1.003 & 0.708 & $E_{\mathrm{g}}=0.29(\mathrm{eV})$ \\
\hline & & & PBE0 & 0.716 & 1.012 & 0.715 & $\mathrm{Eg}=1.36(\mathrm{eV})$ \\
\hline & & & PBEsol0 & 7.08 & 10.01 & 7.07 & $E_{\mathrm{g}}=1.27(\mathrm{eV})$ \\
\hline
\end{tabular}

Ref. Velden, A. \& Jansen, M., Zeitschrift für Anorg. und Allg. Chemie 630, 234-238 (2004). 


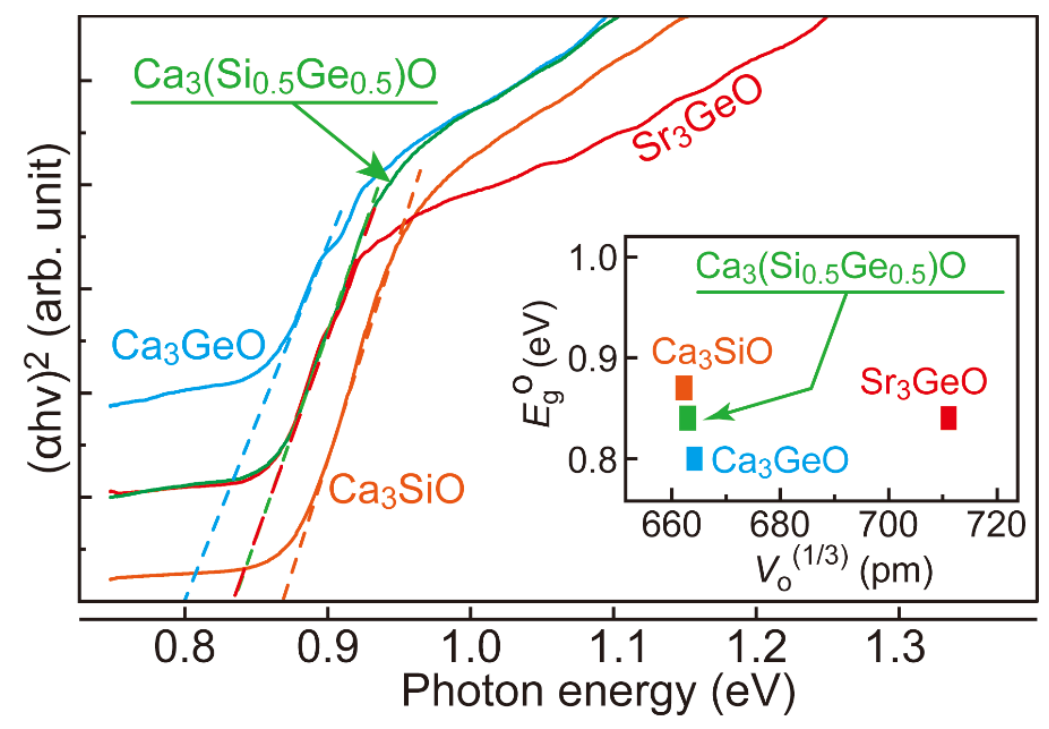

Figure 1 Optical absorption spectra of $R_{3} M O$ samples. The inset shows relationship between cube root of unit cell volume $\left(V_{0}^{1 / 3}\right)$ and optical energy band gap $\left(E_{g}^{o}\right)$ determined from the absorption spectra.

Further optical characterization was performed only for the Mg-free samples. The results of opticalabsorption measurements are shown in Fig. 1. Here, the diffuse reflectance was converted into absorption. The observed absorbance spectra were converted into the Tauc plot shown in the inset of Fig. 1. Optical band gap energy $\left(E_{g}^{o}\right)$ was estimated by assuming a relationship:

$$
(h v \alpha)^{2}=K\left(h v-E_{g}^{o}\right)
$$

Here, $h$ is the Plank's constant, $v$ is frequency, $\alpha$ is absorption coefficient, and $K$ is a constant, and directtransition-type energy band gap is assumed. On this assumption, $E_{g}^{o}$ was estimated from the intercept in Fig. 1. We note that the synthesized $\mathrm{Ca}_{3}\left(\mathrm{Si}_{0.5} \mathrm{Ge}_{0.5}\right) \mathrm{O}$ compound has a band gap energy between that of $\mathrm{Ca}_{3} \mathrm{SiO}$ and $\mathrm{Ca}_{3} \mathrm{GeO}$, indicating that Vegard's law works in this system. On the other hand, an interesting feature found in $R_{3} M O$ compounds prepared in this study was that $E_{g}^{o}$ did not significantly change with chemical composition. It seems that the compounds including heavier element possess a slightly narrower $E_{g}^{o}$ but variation was very 
Inverse perovskite for infrared optics by N. Ohashi et al.

small. That also means that $E_{g}^{o}$ is not significantly sensitive to changes in lattice parameters, as summarized in the inset of Fig. 1. In fact, the lattice parameter of $\mathrm{Sr}_{3} \mathrm{SiO}$ is larger but its $E_{g}^{o}$ is almost the same as that of $\mathrm{Ca}_{3}\left(\mathrm{Si}_{0.5} \mathrm{Ge}_{0.5}\right) \mathrm{O}$.

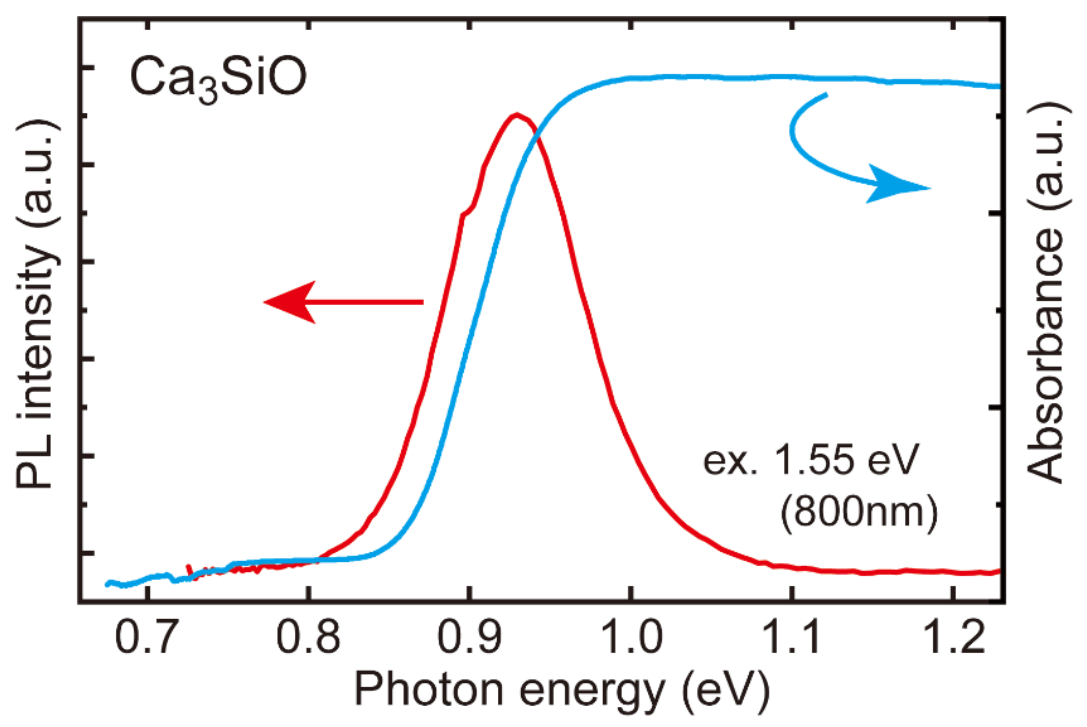

Figure 2 Luminescence spectrumand optical absorbance spectrum of $\mathrm{Ca}_{3} \mathrm{SiO}$ measured at room temperature.

Figure 2 compares the luminescence and absorption spectra of $\mathrm{Ca}_{3} \mathrm{SiO}$ at room temperature. It can be clearly seen that the luminescence peak and the absorption edge energies are very close indicating that the Stokes shift between the absorption and emission peaks is negligibly small. More importantly, this is an experimental evidence that $\mathrm{Ca}_{3} \mathrm{SiO}$ has a direct band gap. At the present stage, we have not evaluated the quantum efficiency of this luminescence, but it is important to note that the luminescence peak was observed even fromthe as -grown powder made by a very conventional solid-state reaction method.

\section{Results of calculations}

The synthesized $\mathrm{Ca}_{3} \mathrm{SiO}$ and other $R_{3} M \mathrm{O}$ compounds exhibited semiconducting properties, e.g., band-edge luminescence, originated in an optical band gap in the range of $0.8-0.9 \mathrm{eV}$. The PBE and PBEsol functionals 
Inverse perovskite for infrared optics by N. Ohashi et al.

indicate, however, that $R_{3} M \mathrm{O}$ compounds have either very small band gaps or exhibit metallic behavior. Using hybrid functionals often helps to reduce the self-interaction error, giving a better representation of the electronic structure and band gaps. The band structures of several compounds calculated using the non-local PBEsol0 functional are shown in Fig. 3. The results confirm that $R_{3} M O$ compounds have direct band gap having both valence band maximum (VBM) and conduction band minimum (CBM) at the $\Gamma$-point. The band diagrams of all four compounds calculated using the PBE0 functional are very similar, as shown in Fig. 3. Therefore, the discussion below is mainly focused on the results of calculations using hybrid functionals.

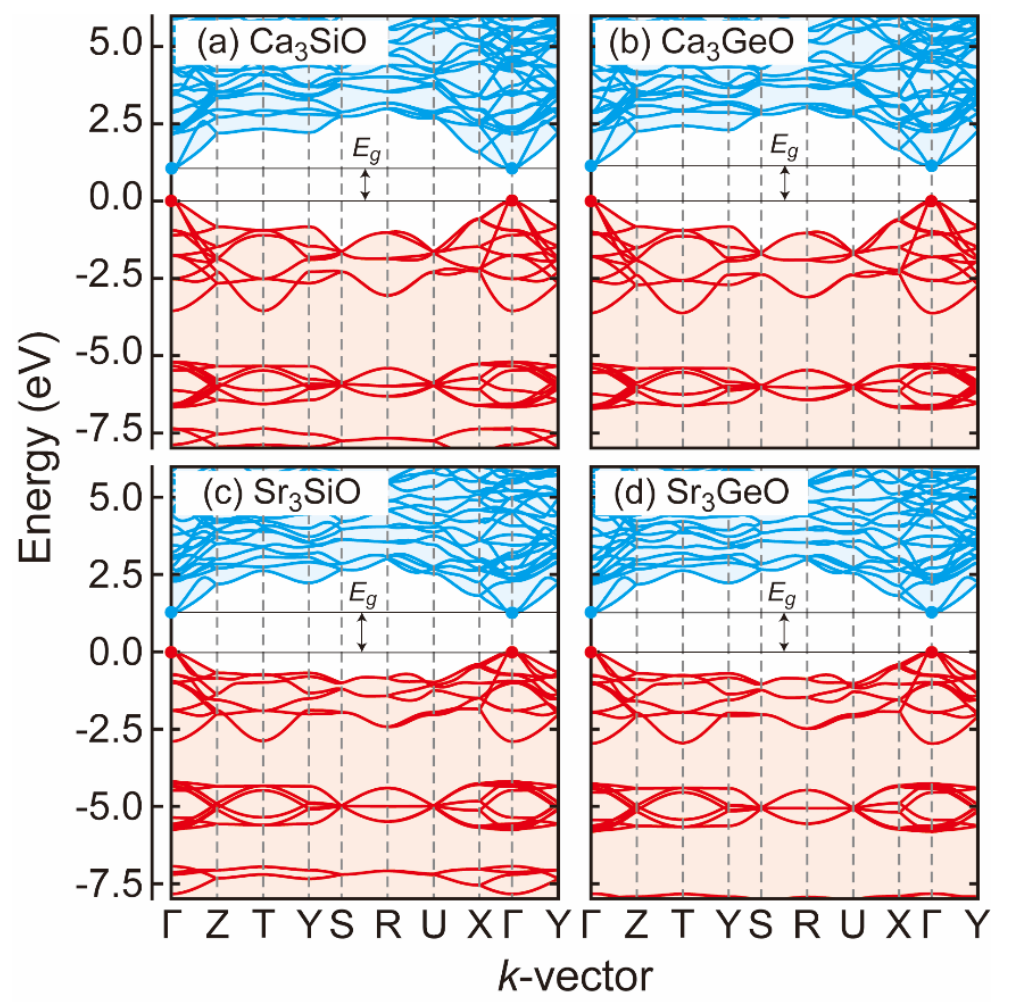

Figure 3 Electron band structure of some $R_{3} M \mathrm{O}(R=\mathrm{Ca}, \mathrm{Sr} ; M=\mathrm{Si}, \mathrm{Ge})$ compounds calculated with PBEsol0 functional. Red and blue hatches indicate occupied and unoccupied states. The valence band maximum (VBM) and conduction band minimum $(\mathrm{CBM})$ are indicated with red and blue dots, respectively, and lines and arrows indicate energy band gap $\left(E_{g}\right)$, which is the energy difference between blue and red dots. 
Inverse perovskite for infrared optics by N. Ohashi et al.

We use the enthalpy of formation as a measure of the compound's stability. Enthalpies $(\Delta H)$ were calculated using total energies of the following reaction:

$$
\mathrm{RO}+\mathrm{Si}+2 \mathrm{R} \rightarrow \mathrm{R}_{3} \mathrm{SiO}(\mathrm{R}=\mathrm{Mg}, \mathrm{Ca}, \mathrm{Sr})
$$

where positive (negative) values indicate an endothermic (exothermic) reaction, i.e. thermodynamically unstable (stable). As in experiment, calculations predict the $\mathrm{Mg}_{3} \mathrm{SiO}$ to be unstable, with $\Delta H=0.42$ and $0.34 \mathrm{eV}$ for the PBE and the PBEsol functionals. This confirms the experimentally observed instability of $\mathrm{Mg}$-rich materials, which is corroborated further below. In contrast, the formation of $\mathrm{Ca}_{3} M \mathrm{O}$ is spontaneous with $\Delta H=-1.43 \mathrm{eV}$ for the PBE and $-1.58 \mathrm{eV}$ for the PBEsol functionals.

Table 2 summarizes the structural properties and the band gaps calculated with the local and non-local functionals of the synthesized inverse-perovskite-type materials. Comparison with the experimental data from previous and current studies is also shown. The calculated PBE lattice parameters are slightly larger than the PBEsol ones. There is no significant variation of the lattice parameters calculated us ing the non-local functionals. The simulated and measured lattice parameters increase with the increase of the atomic number of the $R$-element. This is because there is a positive correlation between the ionic radius of the $R$-element and the atomic number. ${ }^{49,50}$ For instance, the lattice parameters of $\mathrm{Sr}_{3} \mathrm{GeO}$ are larger than those of $\mathrm{Ca}_{3} \mathrm{GeO}$. The lattice parameters are less affected by the substitution of the $M$-elements than the $R$-elements. For example, the unit cell volume of $\mathrm{Sr}_{3} \mathrm{SiO}$ is much larger than that of $\mathrm{Ca}_{3} \mathrm{SiO}$ but $\mathrm{Ca}_{3} \mathrm{SiO}$ and $\mathrm{Ca}_{3} \mathrm{GeO}$ volumes are nearly the same, although atomic radius of $\mathrm{Si}$ is smaller than that of Ge. Variation of the lattice parameters in this manner are in good agreement with the experimental observations presented in Table 2. Hence we can conclude that DFT simulations reproduce well the structural properties of $R_{3} M \mathrm{O}$ compounds.

The band gap energies calculated using non-local functionals are larger than those observed experimentally. We note that we are comparing the difference in the Kohn-Sham energies of the lowest unoccupied molecular orbital and the highest occupied molecular orbital with the optical adsorption spectra. There is no clear correlation between $E_{g}^{o}$ and the chemical composition. As suggested by our h-DFT calculations, the effect on the band gap energy is stronger for the substitution of $R$-element than that of $M$-element, e.g., the band gap increased by $0.1-$ $0.2 \mathrm{eV}$ with $\mathrm{Sr}$ substituting $\mathrm{Ca}$, while it decreased by less than $0.1 \mathrm{eV}$ when Ge substitutes $\mathrm{Si}$. We think this trend 
Inverse perovskite for infrared optics by N. Ohashi et al.

should be general in $R_{3} M \mathrm{O}$ systems. A correlation between the band gap energy and the lattice parameters is discussed below.

The amount of experimental information on the electronic transport properties of our powder materials is limited. We can, however, calculate the effective electron and hole masses from the band structure using Equation 1. In general, materials show relatively small electron and hole effective mas ses (see Table 3), which are favorable properties for electronic applications. Our calculations suggest heavier effective masses for electrons and holes in $R=\mathrm{Sr}$ compared to $R=\mathrm{Ca}$ compounds. The chemical composition effect is discussed in detail in the following section.

Table 3 Effective mass of electron and hole in $R_{3} M O$ compounds estimated from the results of DFT calculations. Notation of symmetry points in momentum space are as $\Gamma$ for $[0.00$, $0.00,0.00], \mathrm{Z}$ for $[0.00,0.00,0.50], \mathrm{X}$ for $[0.00,0.50,0.00]$ and $\mathrm{Y}$ for $[-0.50,0.00,0.00]$, and two values, $\Gamma_{1}$ and $\Gamma_{2}$ are shown when electron bands are degenerated at $\Gamma$-point.

\begin{tabular}{|c|c|c|c|c|c|c|c|}
\hline \multirow{2}{*}{ Compound } & \multirow{2}{*}{ Functional } & \multicolumn{3}{|c|}{ Hole effective mass } & \multicolumn{3}{|c|}{ Electron effective mass } \\
\hline & & $\Gamma-\mathrm{Z}$ & $\Gamma-\mathrm{X}$ & $\Gamma-\mathrm{Y}$ & $\Gamma-Z$ & $\Gamma-\mathrm{X}$ & $\Gamma-\mathrm{Y}$ \\
\hline \multirow{2}{*}{$\mathrm{Ca}_{3} \mathrm{GeO}$} & PBE0 & -0.431 & -0.815 & -0.412 & 0.344 & 0.757 & 0.332 \\
\hline & PBEsol0 & -0.348 & -0.773 & -0.342 & 0.335 & 0.741 & 0.323 \\
\hline \multirow{3}{*}{$\mathrm{da}_{3} \mathrm{SiO}$} & PBE0 & -0369 & -0965 & -0370 & $\Gamma_{1}: 0.401$ & $\Gamma_{1}: 0.751$ & $\Gamma_{1}: 0.385$ \\
\hline & $P B E U$ & -0.309 & -0.965 & $-0.3 / 0$ & $\Gamma_{2}: 0.197$ & $\Gamma_{2}: 0.164$ & $\Gamma_{2}: 0.200$ \\
\hline & PBEsol0 & -0.323 & -0.805 & -0.337 & 0.356 & 0.742 & 0.347 \\
\hline \multirow{2}{*}{$\mathrm{Sr}_{3} \mathrm{GeO}$} & PBE0 & -1.251 & -2.635 & -1.061 & 0.563 & 0.268 & 0.466 \\
\hline & PBEsol0 & -0.849 & -2.321 & -0.604 & 0.537 & 0.263 & 0.447 \\
\hline \multirow{2}{*}{$\mathrm{Sr}_{3} \mathrm{SiO}$} & PBE0 & -1.588 & -2.441 & -1.244 & 0.574 & 0.285 & 0.473 \\
\hline & PBEsol0 & -0.763 & -2.559 & -0.625 & 0.540 & 0.268 & 0.452 \\
\hline \multirow{2}{*}{$\mathrm{Ca}_{3} \mathrm{SnO}$} & PBE0 & $\begin{array}{l}\Gamma_{1}:-0.155 \\
\Gamma_{2}:-0.488\end{array}$ & $\begin{array}{l}\Gamma_{1}:-0.640 \\
\Gamma_{2}:-0.645\end{array}$ & $\begin{array}{l}\Gamma_{1}:-0.155 \\
\Gamma_{2}:-0.488\end{array}$ & 0.274 & 0.731 & 0.274 \\
\hline & PBEsol0 & $\Gamma_{1}:-0.148$ & $\Gamma_{1}:-0.591$ & $\Gamma_{1}:-0.148$ & 0.271 & 0.731 & 0.271 \\
\hline
\end{tabular}


Inverse perovskite for infrared optics by N. Ohashi et al.

Table 4 Results of Bader charges analy sis for $R_{3} M \mathrm{O}$ and $R_{2} M(R=\mathrm{Mg}, \mathrm{Ca}$, or $\mathrm{Sr} ; M=\mathrm{Si}$ or $\mathrm{Ge})$ compounds.

\begin{tabular}{lccc}
\hline \multirow{2}{*}{ Compound } & \multicolumn{3}{c}{ Element / charge $(e)$} \\
& \multicolumn{2}{c}{$\mathrm{O}$} \\
\hline $\mathrm{Ca}_{3} \mathrm{SiO}$ & $\mathrm{Ca} / 1.35$ & $\mathrm{Si} /-2.50$ & -1.54 \\
$\mathrm{Ca}_{3} \mathrm{GeO}$ & $\mathrm{Ca} / 1.32$ & $\mathrm{Ge} /-2.40$ & -1.55 \\
$\mathrm{Sr} 3 \mathrm{SiO}$ & $\mathrm{Sr} / 1.32$ & $\mathrm{Si} /-2.40$ & -1.55 \\
$\mathrm{Sr}_{3} \mathrm{GeO}$ & $\mathrm{Sr} / 1.32$ & $\mathrm{Ge} /-2.40$ & -1.55 \\
$\mathrm{Mg}_{3} \mathrm{SiO}$ & $\mathrm{Mg} / 1.32$ & $\mathrm{Si} /-2.40$ & \\
$-\mathrm{Ca}_{2} \mathrm{Si}$ & $\mathrm{Ca} / 1.25$ & $\mathrm{Si} /-2.57$ & \\
$\mathrm{Ca}_{2} \mathrm{Ge}$ & $\mathrm{Ca} / 1.25$ & $\mathrm{Ge} /-2.56$ & \\
$\mathrm{Sr}_{2} \mathrm{Si}$ & $\mathrm{Sr} / 1.19$ & $\mathrm{Si} /-2.44$ & \\
$\mathrm{Sr}_{2} \mathrm{Ge}$ & $\mathrm{Sr} / 1.18$ & $\mathrm{Ge} /-2.43$ & \\
$\mathrm{Mg}_{2} \mathrm{Ge}^{*}$ & $\mathrm{Mg} / 1.2$ & $\mathrm{Ge} /-2.65$ & \\
$\mathrm{Mg}_{2} \mathrm{Si}^{*}$ & $\mathrm{Mg} / 1.50$ & $\mathrm{Si} /-3.00$ & \\
\hline
\end{tabular}

* Fluorite-type structure

The results of Bader analys is of ionic charges are summarized in Table 4 . They demonstrate that $R_{3} M \mathrm{O}$ are highly ionic crystals. The values for $R$ and $\mathrm{O}$ shown in Table 4 are close to those in oxides characterized by their ionic bonding, e.g., $+1.69 e$ for $\mathrm{Mg}$ in $\mathrm{MgO},{ }^{51}+1.56 e$ for $\mathrm{Ca}$ in $\mathrm{CaTiO}_{3},{ }^{52}+1.61$ e for $\mathrm{Sr}$ in $\mathrm{SrTiO}_{3},{ }^{52}+1.7 e$ for $\mathrm{Ba}$ and in $\mathrm{Ba}_{2} \mathrm{TiSi}_{2} \mathrm{O}_{8},{ }^{53}+1.7$ e for $\mathrm{Ba}$ in $\mathrm{BaTiO}_{3} .{ }^{53}$ Consequently, effective charges of $M$-elements have to be negative and large for compensation. We note that the Bader charge of Si in silicates is close to $+2.3 e$, whereas its formal charge is $+4 e .^{53}$ However, $M$-elements in $R_{3} M O$ are unquestionably anions with negative effective charges exceeding $-2.4 e$. It is also interesting to note that effective charges of $\mathrm{Sr}$ and $\mathrm{Ca}$ shown in Table 4 are close to each other regardless of $M$ and that effective charge of Si and Ge are almost same regardless of $R$. This may be the reas on for very similar band structures of $R_{3} M \mathrm{O}(R=\mathrm{Sr}, \mathrm{Ca}$, and $M=\mathrm{Si}, \mathrm{Ga})$. On the other hand, the $\mathrm{Mg}$ and $\mathrm{Si}$ Bader charges in $\mathrm{Mg}_{3} \mathrm{SiO}$ are clearly different from those of the other compounds. This is a good indication that chemical bonds involving $\mathrm{Mg}$ in $R_{3} M \mathrm{O}$ are quite different from those involving $\mathrm{Ca}$ and $\mathrm{Sr}$ in $R_{3} M \mathrm{O}$. This peculiar behavior of $\mathrm{Mg}$ correlates with the instability of $\mathrm{Mg}_{3} M \mathrm{O}$.

\section{Discussion}

Measured and calculated structural parameters of $R_{3} M O$ suggest that the lattice parameters of these compounds are governed by the $R-\mathrm{O}$ bond length. The calculated $R-\mathrm{O}$ distances are $255 \mathrm{pm}$ for $\mathrm{Sr}_{3} M \mathrm{O}$ and $236-$ 
Inverse perovskite for infrared optics by N. Ohashi et al.

$237 \mathrm{pm}$ for $\mathrm{Ca}_{3} M \mathrm{O}$, which are in close agreement with those measured by single crystalx-ray diffraction..$^{29,30}$ It has to be noted that these values are very close to the $R-\mathrm{O}$ distances in $\mathrm{SrO}$ and $\mathrm{CaO}$ with rock-salt structure, ${ }^{54}$ suggesting that the $R-\mathrm{O}$ bonds in $R_{3} M \mathrm{O}$ compounds are very similar to those in typical oxides. This implies that the $M$-elements have to be anions to compensate positive charge of the $R$-elements, which is also demonstrated by the Bader population analysis discussed above. On the other hand, the lattice parameters of the $R_{3} M O$ compounds are not sensitive to substitution of $M$-elements. The inter-atomic distances in $\mathrm{Si}$ and $\mathrm{Ge}$ in the diamond structure are within about $235 \mathrm{pm}$ and $246 \mathrm{pm}$ and their band gap energies are 1.1 and $0.67 \mathrm{eV}$, respectively. In contrast, the $M-M$ interatomic distances change only with substitution of the $R$-element and $M-$ $M$ distances are not sensitive to substitution of $M$-element. For example, the $\mathrm{Si}-\mathrm{Si}$ and $\mathrm{Ge}-\mathrm{Ge}$ distances in $\mathrm{Sr}_{3} \mathrm{SiO}$ and $\mathrm{Sr}_{3} \mathrm{GeO}$ differ only by $2 \mathrm{pm}$. Hence, we can conclude that the lattice parameters of the $R_{3} M \mathrm{O}$ materials are determined by the $R-\mathrm{O}$ bond length.

This consideration is supported by the local density of states (LDOS). Figure 4 shows the results of LDOS analys is for $\mathrm{Sr}_{3} \mathrm{SiO}$ calculated using the PBEsol0 functional. Additional results of LDOS calculations are shown in Fig. S-2 in the Supporting Information. Here, O- $p$ electronic states are found to be about $4-7$ eV below the valence band maximum (VBM), whereas the conduction band minimum (CBM) is composed of $d$ states of the $R$-elements. Thus the $\mathrm{O}-2 p$ oxygen states (O-p in Figure 4$)$ form a deepervalence band. On the other hand, the top of the valence band at $0-3.5 \mathrm{eV}$ is dominated by $p$ states of $M$-elements. This implies that the electronic structure of $R_{3} M \mathrm{O}$ compounds can be viewed as a superposition of electronic structures attributed to $R_{2} M$ component, having a narrow band gap, and that of $R \mathrm{O}$ with a wider band gap and the resulting band gap of $R_{3} M O$ is determined by that of the $R_{2} M$-component. The energy band gap of $\mathrm{CaO}$ was experimentally determined to be $7.1 \mathrm{eV}^{55}$ and calculated to be $6.6 \mathrm{eV}$ within the $\mathrm{GW}$ approximation; ${ }^{56}$ for $\mathrm{SrO}$, it is approximately $6 \mathrm{eV}$ from observed reflection spectra, ${ }^{57}$ and $7.24 \mathrm{eV}$ with in the GW approximation. ${ }^{58}$ The energy differences between CBM and the top edge of $\mathrm{O}-2 p$ bands calculated for $R_{3} M \mathrm{O}$ compounds are very similar, as shown in Figs. 4 and S-2. The dispersion of electron energy in momentum space does not seem to change by elemental substitution either (see Fig. 3). There is no difference between $\mathrm{Sr}_{3} \mathrm{GeO}$ and $\mathrm{Sr}_{3} \mathrm{SiO}$ band structures to the naked eye. 


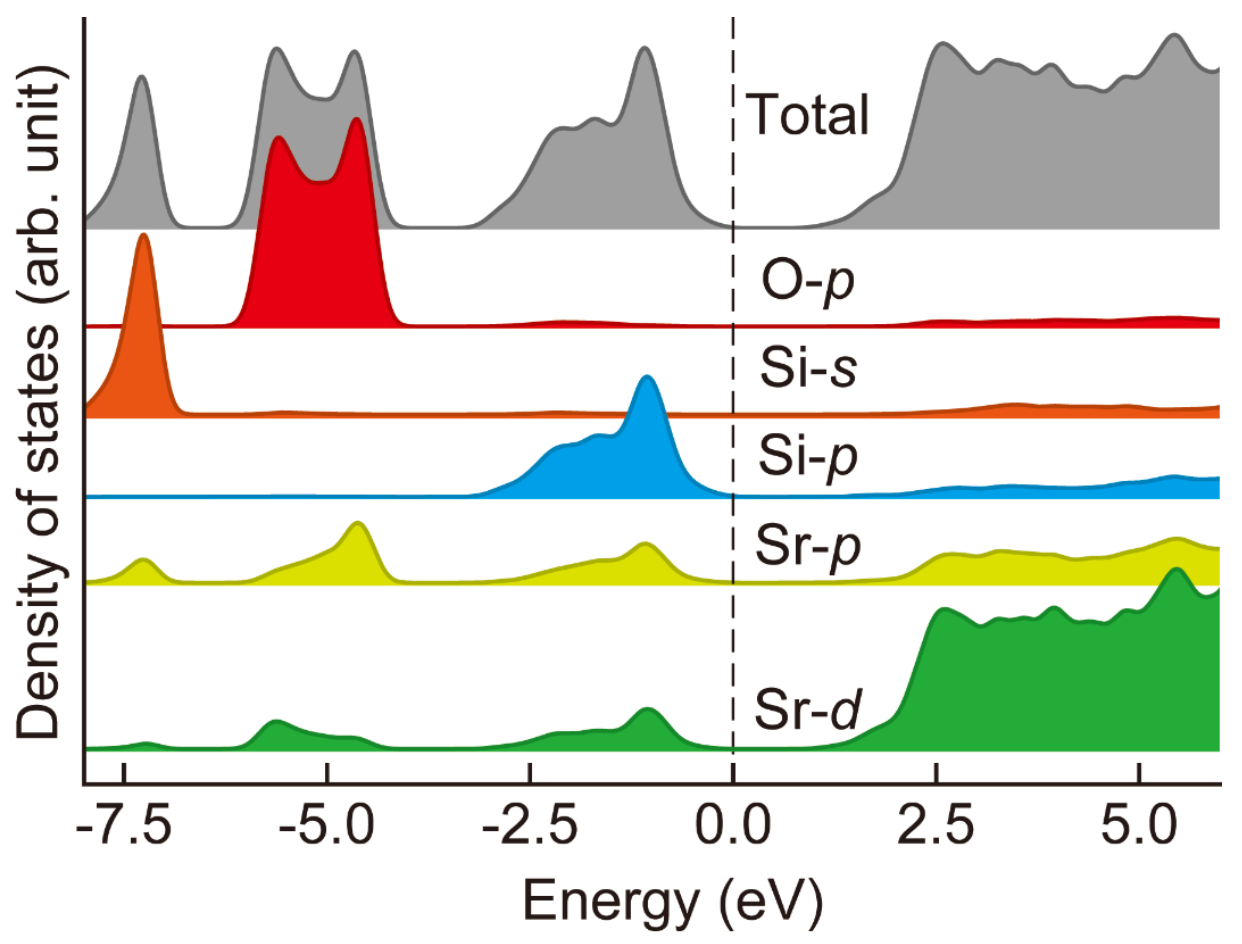

Figure 4 Local density of states (LDOS) for $\mathrm{Sr}_{3} \mathrm{SiO}$ calculated using PBEsol0 functional. The vertical scale are in arbitrary unit for visibility.

The geometric and electronic structures of $R_{3} M O$ compounds demonstrate that these are ionic crystals where $M$-elements serve as anions with $-4 e$ formal charge, but the band dispersion of $M$-elements is very similar to that for $\mathrm{Si}$ and Ge. Analys is of the $R_{2} M$ electronic structure supports our assertion that the electronic structure of $R_{3} M \mathrm{O}$ can be viewed as that of the $R_{2} M$ component with a narrow band gap being superimposed onto that of the $R \mathrm{O}$ component with a wider band gap and that substitution of $M$-elements does not affect electronic structures because of the strong ionic characteristics of $M^{4-}$ anions. Figure 5 shows $\mathrm{DOS}$ for $\mathrm{Ca}_{2} \mathrm{Ge}^{59}{ }^{59} \mathrm{Ca}_{2} \mathrm{Si}^{5}{ }^{59} \mathrm{Mg}_{2} \mathrm{Si}$ $(F \mathrm{~m} 3 m)^{60}, \mathrm{Mg}_{2} \mathrm{Ge}(F \mathrm{~m} 3 \mathrm{~m}),{ }^{61} \mathrm{Sr}_{2} \mathrm{Si}^{62}$ and $\mathrm{Sr}_{2} \mathrm{Ge}^{63}$ compounds calculated using the PBEsol0 functional. As seen in the top and middle panels, the Ge/Si substitution has a minor effect on the DOS. In addition, the main features of the DOS profile of the compounds with $R=\mathrm{Ca}$ are very similar to those with $R=\mathrm{Sr}$. The effect of elemental substitution shown here is very similar to that shown in Fig. 3 and Figs. S-2 in supporting information. It seems that $M^{4-}$ anions behave like point charges and their contribution to the band dispersion and band-gap is minor compared to that of the Madelung potential. This idea is also supported by comparing the results of Bader 
Inverse perovskite for infrared optics by N. Ohashi et al.

population analys is for $R_{3} M \mathrm{O}$ and $R_{2} M$ shown in Table 4 . The effective charges of $R$ and $M$ in those compounds are very similar to each other demonstrating that both $R_{3} M \mathrm{O}$ and $R_{2} M$ are highly ionic crystals. The fact that the band structures of $R_{3} M \mathrm{O}$ and $R_{2} M$ do not change with $R$ and $M$ substitution is likely a cause for the very small change of the $R_{3} M O$ energy band gap by $M$-element substitution seen in Fig. 1 and Table 2.

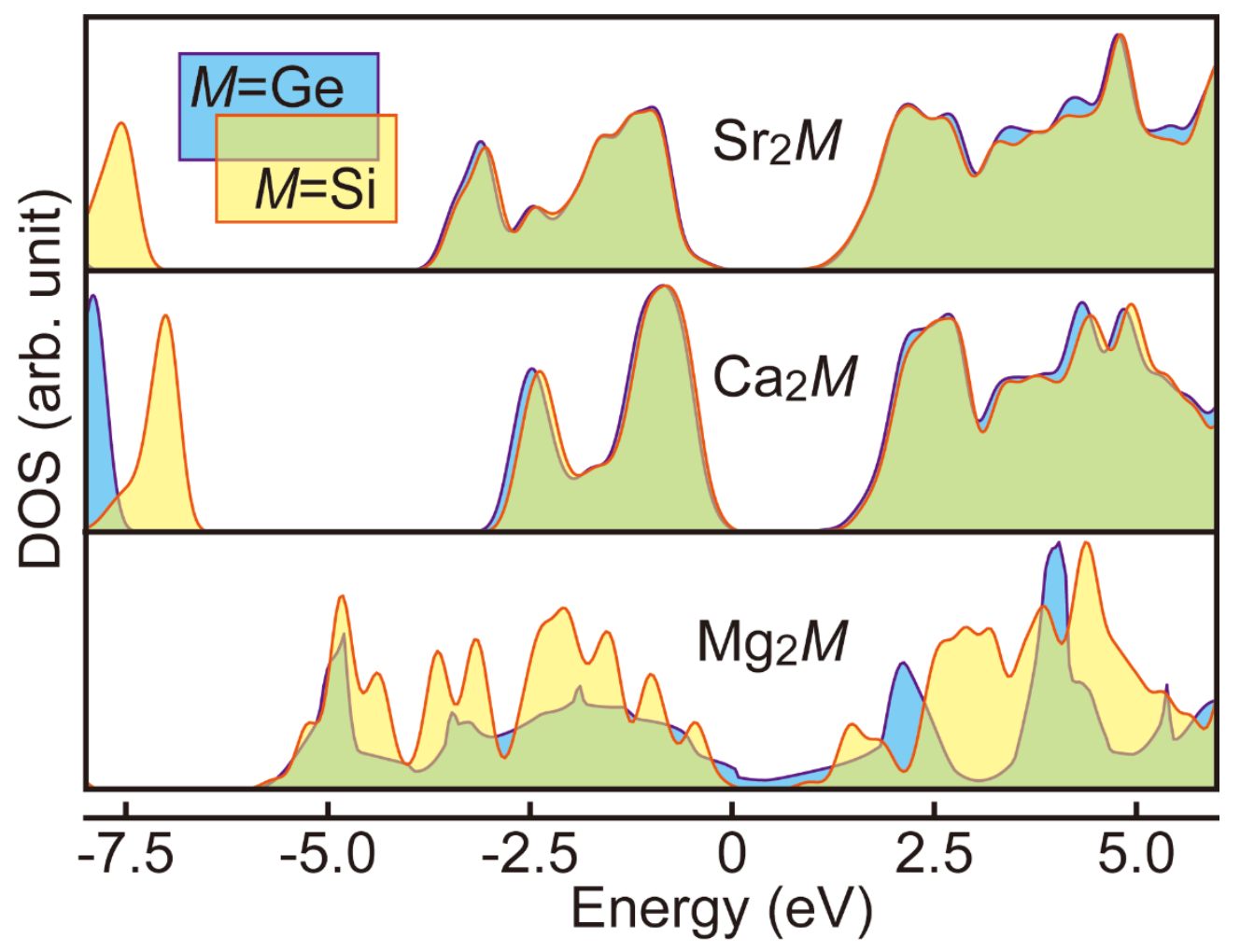

Figure 5 Density of states (DOS) for some $R_{2} M$ compounds $(R=\mathrm{Mg}, \mathrm{Ca}$ or $\mathrm{Sr} ; M=\mathrm{Si}$ or $\mathrm{Ge})$ calculated by using PBEsol0 functional. Calculation for $\mathrm{Mg}_{2} M$ were performed for one of reported polymorphs, the fluorite-type structure.

We note that the electronic structure of $\mathrm{Mg}_{2} M$ compounds with fluorite structure (bottom panel in Fig. 5) is different from other $R_{2} M$ compounds studied here. Indeed, the DOS dispersion for $\mathrm{Mg}_{2} \mathrm{Si}$ is clearly different from those for the other two compounds. The most critical difference between $\mathrm{Mg}$ and other $R$-elements is in the lowest excited states. The excited orbital of $\mathrm{Mg}$ is $3 p$ states, while for $\mathrm{Sr}$ and $\mathrm{Ca}$ these are $4 d$ and $3 d$ states, respectively. This may be the reason for the difference between $\mathrm{Mg}_{2} M$ and other $R_{2} M$ electronic structures. Further band gap tuning of $R_{3} M \mathrm{O}$ could be achieved by substituting $\mathrm{Mg}$ for $\mathrm{Ca}$ to make lattice parameter smaller. Unfortunately, as shown above, $\mathrm{Mg}$ does not dissolve in the $R_{3} M \mathrm{O}$ lattice. The most obvious difference between $\mathrm{Mg}$ and the 
Inverse perovskite for infrared optics by N. Ohashi et al.

other alkali earth elements is that $\mathrm{Mg}$ is on the third raw in the periodic table and there is a lack of $d$ orbitals, while the first excited states of $\mathrm{Ca}$ and $\mathrm{Sr}$ are $3 d$ and $4 d$ orbital, respectively. This suggests that the contribution of $d$ orbitals to chemical bonding is essential for the stability of $R_{3} M O$ compounds with inverse-perovskite-type structure. Since $R-\mathrm{O}$ bonds in $R_{3} M \mathrm{O}$ and rock-salt compounds are very similar, we can draw an analogy between the nature of the $R-\mathrm{O}$ bonds in $R_{3} M \mathrm{O}$ and $M \mathrm{O}$ compounds. In this context, we refer to the phase diagram of $\mathrm{MgO}-\mathrm{CaO}$ pseudo-binary system. ${ }^{64,65} \mathrm{It}$ is evident that solubility of $\mathrm{CaO}$ in $\mathrm{MgO}$ or $\mathrm{MgO}$ in $\mathrm{CaO}$ is very narrow and the wide miscibility gap opens up in this pseudo-binary system. This $\mathrm{MgO}-\mathrm{CaO}$ miscibility indicates that formation of $(\mathrm{Ca}, \mathrm{Mg})_{3} \mathrm{MO}$ should be very difficult. On the other hand, the pseudo binary $\mathrm{CaO}-\mathrm{SrO}$ phase diagram has a wide solid solution range at relatively low temperature. ${ }^{66}$ The large miscibility gap between $\mathrm{MgO}$ and $\mathrm{CaO}$ has been attributed to absence of $d$ orbitals in $\mathrm{Mg}$. Therefore, tuning of semiconductor lattice parameters via adjusting $R-\mathrm{O}$ chemical bonds by elemental substitution using $\mathrm{Mg}$ is very difficult.

Finally, we briefly discuss the band alignment of $R_{3} M \mathrm{O}$ compounds. Since the electronic structure of $R_{3} M \mathrm{O}$ possesses characteristics of both $R \mathrm{O}$ and $R_{2} M$, one can use the band diagram of the $R_{2} M$ and $R \mathrm{O}$ compounds to align them with the corresponding $R_{3} M \mathrm{O}$ energy states, and thus, estimate their ionization potential and electron affinity. The experimental bulk ionization potential of $\mathrm{CaO}$ and $\mathrm{SrO}$ is 6.25 and $5.30 \mathrm{eV}$, which is in good agreement with those calculated with highly accurate DFT calculations using hybrid functionals ${ }^{67,68}$ Note that the ionization potential for those typical oxides are calculated using the VBM energy, which is mainly composed of $\mathrm{O}-2 p$ band, with respect to the vacuum level. Hence, the ionization energy of the $R_{3} M \mathrm{O}$ compounds was estimated by aligning the top of the $\mathrm{O}-2 p$ band in $R_{3} M \mathrm{O}$ to the ionization potential of $\mathrm{CaO}$ and $\mathrm{SrO}$, as shown in Fig. 6. The calculated top of the $\mathrm{O}-2 p$ band in $R_{3} M \mathrm{O}$ is about $5.0 \mathrm{eV}$ below $\mathrm{VBM}$ for $R=\mathrm{Ca}$ and $4.1 \mathrm{eV}$ for $R=\mathrm{Sr}$ (see Figs. 3, 4, and S-2). Therefore, the ionization potential for $R_{3} M \mathrm{O}(R=\mathrm{Ca}$ or $\mathrm{Sr}$ ) compounds is estimated to be around $1.20-1.25 \mathrm{eV}$. This value is relatively small, which encourages us to work on doping through hole injection. Moreover, these materials are expected to show good catalytic properties. We note that analysis of the $R_{3} M O$ refractive indexes is beyond the scope of the current work. This is, however, needed to construct optical devices based on these materials. Further investigation on $R_{3} M \mathrm{O}$ solid solutions is in progress and will be reported in a separate publication. 


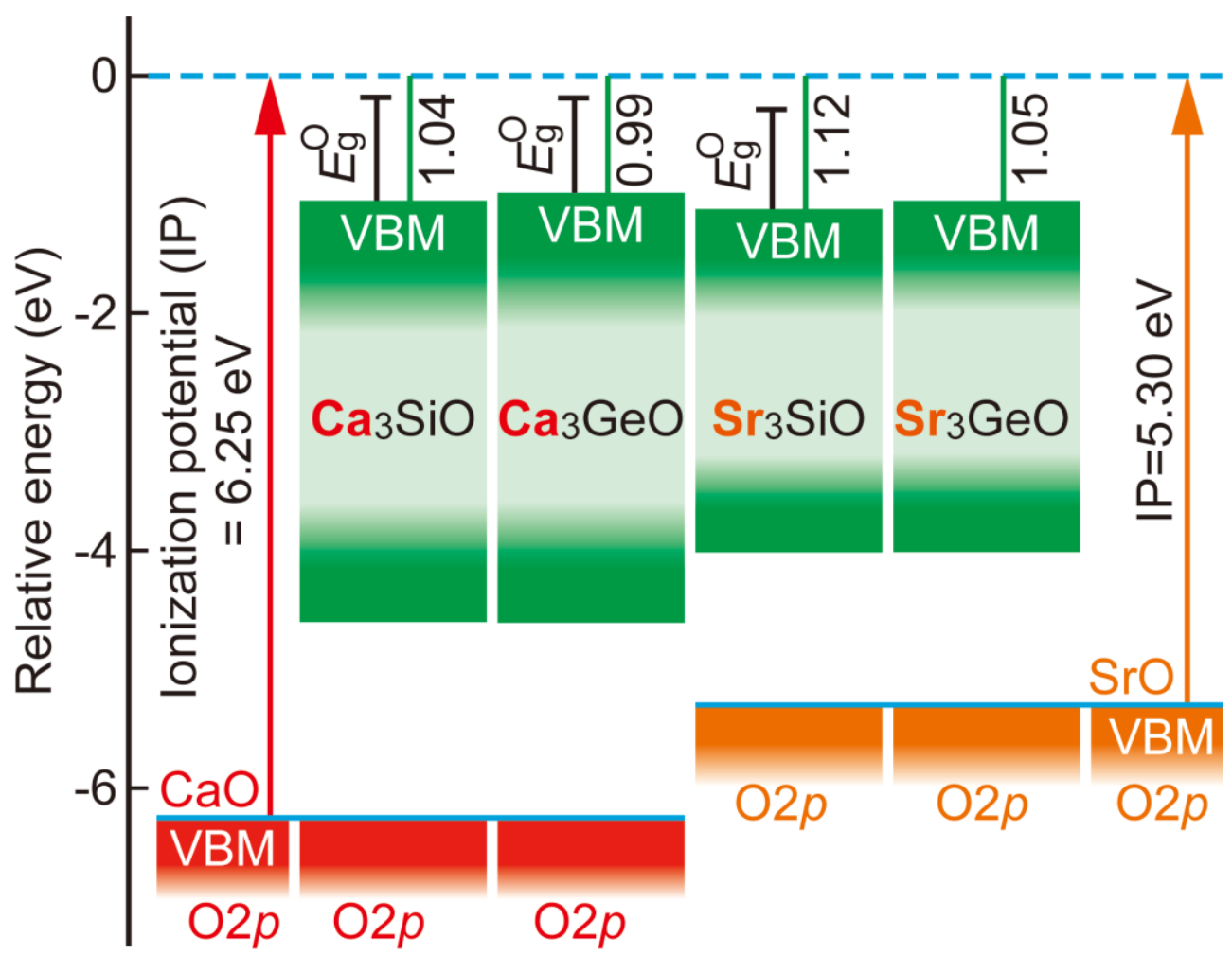

Figure 6 Estimation ofionization potential for $R_{3} M \mathrm{O}(R=\mathrm{Ca}$ or $\mathrm{Sr} ; M=\mathrm{Si}$ or Ge $)$ by aligning calculated high energy ends of the $\mathrm{O}-2 p$ band to the valence band maximum (VBM) of known $R \mathrm{O}$ compounds. Vacuum level is set to zero in energy scale and the lengths ofthe bardenotedby $E_{g}^{o}$ indicate experimentally determined energy band gap.

\section{Conclusions}

We have synthesized inverse-perovskite-type oxysilicides and oxygermanides, $R_{3} M \mathrm{O}(R=\mathrm{Ca}, \mathrm{Sr} ; M=\mathrm{Si}, \mathrm{Ge})$, and investigated their optical properties. The materials are semiconductors with a direct optical band gap, as suggested by their optical absorption edges and luminescence spectra. These findings were corroborated by hybrid DFT calculations, where a direct band gap was calculated from their band structures. Band gaps are determined to be $0.8-0.9 \mathrm{eV}$, with no significant change upon elemental substitution. This feature is driven by their structural properties, in particular the $M-M$ bond distances. It is also shown that incorporation of $M g$ into $R_{3} M \mathrm{O}$ lattice is energetically unfavorable. That is a limitation for optoelectronic device applications of $R_{3} M O$ 
Inverse perovskite for infrared optics by N. Ohashi et al.

compounds since band gap engineering is limited. In contrast, relatively small ionization potentials of $R_{3} M O$ compounds are estimated, which is another interesting feature for practical applications.

To summarize, we have synthesized a new class of materials with potential applications as semiconductors in IR devices. These materials are made from earth abundant and non-toxic elements, with relatively light electron/hole effective mass and a direct band gap. Our findings represent, therefore, a big step into the design of new non-toxic materials with high functionality.

\section{Acknowledgements}

This study was partly supported by MEXT Element Strategy Initiative to Form Core Research Center (Grant Number JPMXP0112101001). We are grateful to JSPS and EPSRC for support under the core-to-core scheme, project "Defect Functionalized Sustainable Energy Materials: From Design to Devices Application" (EPSRC grant EP/R034540/1). We also acknowledge funding provided by EPSRC under grant EP/P013503/1 and by JSPS grant \#JPJSCCA20180006. Via our membership of the UK's HEC Materials Chemistry Consortium, which is funded by EPSRC (EP/L000202), this work used the UK Materials and Molecular Modelling Hub for computational resources, MMM Hub, which is partially funded by EPSRC (EP/P020194). 


\section{References}

(1) Koyama, F. Recent Advances of VCSEL Photonics. J. Light. Technol. 2006, 24 (12), 4502-4513. https://doi.org/10.1109/JLT.2006.886064.

(2) Campbell, J. C.; Demiguel, S.; Ma, F.; Beck, A.; Guo, X.; Wang, S.; Zheng, X.; Li, X.; Beck, J. D.; Kinch, M. A.; Huntington, A.; Coldren, L. A.; Decobert, J.; Tscherptner, N. Recent Advances in Avalanche Photodiodes. IEEE J. Sel. Top. Quantum Electron. 2004, 10 (4), 777-787. https://doi.org/10.1109/JSTQE.2004.833971.

(3) Rogalski, A.; Antoszewski, J.; Faraone, L. Third-Generation Infrared Photodetector Arrays. J. Appl. Phys. 2009, 105(9), 091101. https://doi.org/10.1063/1.3099572.

(4) Rogalski, A. Infrared Detectors: Status and Trends. Prog. Quantum Electron. 2003, 27 (2-3), 59-210. https://doi.org/10.1016/S0079-6727(02)00024-1.

(5) Boening, D. W. EcologicalEffects, Transport, and Fate of Mercury: A General Review. Chemosphere 2000, 40 (12), 1335-1351. https://doi.org/10.1016/S0045-6535(99)00283-0.

(6) Järup,L.; Åkesson, A. Current Status of Cadmiumas an Environmental Health Problem. Toxicol. Appl. Pharmacol. 2009, 238(3), 201-208. https://doi.org/10.1016/j.taap.2009.04.020.

(7) Stohs, S. Oxidative Mechanisms in the Toxicity of Metal Ions. Free Radic. Biol. Med. 1995, 18 (2), 321336. https://doi.org/10.1016/0891-5849(94)00159-H.

(8) Taylor, A. Biochemistry of Tellurium. Biol. Trace Elem. Res. 1996, 55 (3), 231-239. https://doi.org/10.1007/BF02785282.

(9) Johnson, J. L.; Samoska, L. A.; Gossard, A. C.; Merz, J. L.; Jack, M. D.; Chapman, G. R.; Baumgratz, B. A.; Kosai, K.; Johns on, S. M. Electrical and Optical Properties of Infrared Photodiodes Using the InAs/ $\mathrm{Ga}_{1_{-} \mathrm{I}} \mathrm{In}_{\mathrm{x}} \mathrm{Sb}$ Superlattice in Heterojunctions with GaSb. J. Appl. Phys. 1996, 80 (2), 1116-1127. https://doi.org/10.1063/1.362849.

(10) Jeon, H.; Ding, J.; Nurmikko, A. V.; Xie, W.; Grillo, D. C.; Kobayashi, M.; Gunshor, R. L.; Hua, G. C.; Otsuka, N. Blue and Green Diode Lasers in ZnSe- based QuantumWells. Appl. Phys. Lett. 1992, 60 (17), 2045-2047. https://doi.org/10.1063/1.107109.

(11) Butté, R.; Carlin, J. F.; Feltin, E.; Gonschorek, M.; Nicolay, S.; Christmann, G.; Simeonov, D.; Castiglia, A.; Dorsaz, J.; Buehlmann, H. J.; Christopoulos, S.; Baldassarri Höger Von Högersthal, G.; Grundy, A. J. D.; 
Inverse perovskite for infrared optics by N. Ohashi et al.

Mosca, M.; Pinquier, C.; Py, M. A.; Demangeot, F.; Frandon, J.; Lagoudakis, P. G.; Baumberg, J. J.;

Grandjean, N. Current Status of AlInN Layers Lattice-Matched to GaN for Photonics and Electronics. J.

Phys. D. Appl. Phys. 2007, 40 (20), 6328-6344. https://doi.org/10.1088/0022-3727/40/20/S16.

(12) Kondow, M.; Kitatani, T.; Nakatsuka, S.; Larson, M.C.; Nakahara, K.; Yazawa, Y.; Okai, M.; Uomi, K.

GaInNAs: A Novel Material for Long-W aveleng th Semiconductor Lasers. IEEE J. Sel. Top. Quantum

Electron. 1997, 3 (3), 719-730. https://doi.org/10.1109/2944.640627.

(13) Zhang, S. B.; Wei, S.-H.; Zunger, A.; Katayama-Yoshida, H. Defect Physics of the CuIn $\mathrm{Se}_{2}$ Chalcopyrite Semiconductor. Phys. Rev. B 1998, 57 (16), 9642-9656. https://doi.org/10.1103/PhysRevB.57.9642.

(14) Pers son, C.; Zhao, Y.-J.; Lany, S.; Zunger, A. N-Type Doping of CuInSe 2 and $\mathrm{CuGaSe}_{2}$. Phys. Rev. B 2005, 72 (3), 035211. https://doi.org/10.1103/PhysRevB.72.035211.

(15) Jackson,P.; Wuerz, R.; Hariskos, D.; Lotter,E.; Witte, W.; Powalla, M.Effects of Heavy Alkali Elements in $\mathrm{Cu}(\mathrm{In}, \mathrm{Ga}) \mathrm{Se} 2$ SolarCells with Efficiencies up to 22.6\%. Phys. status solidi-RapidRes. Lett. 2016, 10 (8), 583-586. https://doi.org/10.1002/pssr.201600199.

(16) Morris, R. G.; Redin, R. D.; Danielson, G. C. Semiconducting Properties of $\mathrm{Mg}_{2} \mathrm{Si}$ Single Cry stals. Phys. Rev. 1958,109(6), 1909-1915. https://doi.org/10.1103/PhysRev.109.1909.

(17) Hao, J. H.; Guo, Z. G.; Jin, Q. H. First Principles Calculation of Structural Phase Transformation in $\operatorname{Mg}_{2} \mathrm{Si}_{\text {at }}$ High Pres sure. Solid State Commun. 2010, 150(47-48), 2299-2302.

https://doi.org/10.1016/j.ssc.2010.10.017.

(18) El-Amir, A. A. M.; Ohsawa, T.; Ishii, S.; Imura, M.; Liao, M.; Fu, X.; Segawa, H.; Sakaguchi, I.; Nagao, T.; Shimamura, K.; Ohashi, N. Silicon-Compatible $\mathrm{Mg}_{2} \mathrm{Si} / \mathrm{Si}$ - $p$ Photodiodes with High RoomTemperature Infrared Res ponsivity. Mater. Sci. Semicond. Process. 2019, 102 (June), 104577. https://doi.org/10.1016/j.ms sp.2019.06.012.

(19) Akasaka, M.; Iida, T.; Matsumoto, A.; Yamanaka, K.; Takanashi, Y.; Imai, T.; Hamada, N. The Thermoelectric Properties of Bulk Cry stalline $n$ - and $p$-Type $\mathrm{Mg}_{2} \mathrm{Si}$ Prepared by the Vertical Bridgman Method. J. Appl. Phys. 2008, 104(1), 013703. https://doi.org/10.1063/1.2946722.

(20) Stella, A.; Lynch, D. W. Photoconductivity in $\mathrm{Mg}_{2}$ Si and $\mathrm{Mg}_{2}$ Ge. J. Phys. Chem. Solids 1964, 25 (11), 12531259. https ://doi.org/10.1016/0022-3697(64)90023-X. 
Inverse perovskite for infrared optics by N. Ohashi et al.

(21) Janka, O.; Zaikina, J. V.; Bux, S. K.; Tabatabaifar, H.; Yang, H.; Browning, N. D.; Kauzlarich, S. M. Micros tructure Investigations of $\mathrm{Yb}$ - and Bi-Doped $\mathrm{Mg}_{2} \mathrm{Si}$ Prepared from Metal Hydrides for Thermoelectric Applications. J. Solid State Chem. 2017, 245, 152-159. https://doi.org/10.1016/j.js sc.2016.10.011.

(22) Mahan, J.E.; Vantomme, A.; Langouche, G.; Becker, J. P. Semiconducting Mg2SiThin Films Prepared by Molecular-BeamEpitaxy. Phys. Rev. B 1996, 54 (23), 16965-16971. https://doi.org/10.1103/PhysRevB.54.16965.

(23) Baranek, P.; Schamps, J. Influence of Electronic Correlation on Structural, Dynamic, and Elas tic Properties of Mg2Si. J. Phys. Chem. B 1999, 103(14), 2601-2606. https://doi.org/10.1021/jp982114r.

(24) Imai, Y.; Watanabe, A.; Mukaida, M. Electronic Structures of Semiconducting Alkaline-Earth Metal Silicides. J. Alloys Compd. 2003, 358(1-2), 257-263. https ://doi.org/10.1016/S0925-8388(03)00037-9.

(25) Miyazaki, H. T. Unconventional ThermalEmis sion fromPhotonic Crystals. In Micro-andNanophotonic Technologies; Meyrueis, P., Voorde, M. Van de, Sakoda, K., Eds.; Wiley-VCH Verlag GmbH \& Co. KGaA: Weinheim, Germany, 2017; pp 51-64. https://doi.org/10.1002/9783527699940.ch3.

(26) Miyazaki,H. T.; Mano, T.; Kasaya, T.; Osato, H.; Watanabe, K.; Sugimoto, Y.; Kawazu, T.; Arai, Y.; Shigetou, A.; Ochiai, T.; Jimba, Y.; Miy azaki, H. Synchronously Wired Infrared Antennas for Resonant Single-Quantum-Well Photodetection up to RoomTemperature. Nat. Commun. 2020, 11 (1), 565. https://doi.org/10.1038/s41467-020-14426-6.

(27) Pöhls, J.-H.; Mar, A. Thermoelectric Properties of Inverse Perovskites $A_{3} T t \mathrm{O}(A=\mathrm{Mg}, \mathrm{Ca} ; \mathrm{Tt}=\mathrm{Si}, \mathrm{Ge})$ : Computational and Experimental Investigations. J. Appl. Phys. 2019, 126 (2), 025110. https://doi.org/10.1063/1.5095247.

(28) Oudah, M.; Ikeda, A.; Hausmann, J. N.; Yonezawa, S.; Fukumoto, T.; Kobayashi, S.; Sato, M.; Maeno, Y.

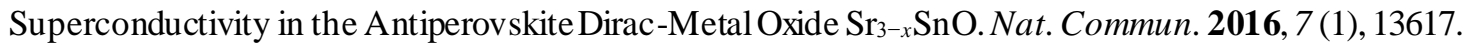
https://doi.org/10.1038/ncomms 13617.

(29) Huang, B.; Corbett, J. D. Orthorhombic Inverse Perovskitic $\mathrm{Ba}_{3} T t \mathrm{O}(T t=\mathrm{Ge}, \mathrm{Si})$ as Zintl Phases. Zeitschrift für Anorg. undAllg. Chemie 1998, 624 (11), 1787-1790. https://doi.org/10.1002/(SICI)15213749(1998110)624:11<1787::AID-ZAAC1787>3.0.CO;2-P.

(30) Velden, A.; Jansen, M.Zur Kenntnis Der Inversen Perowskite $M_{3} T \mathrm{O}(M=\mathrm{Ca}, \mathrm{Sr}, \mathrm{Yb} ; T=\mathrm{Si}, \mathrm{Ge}, \mathrm{Sn}, \mathrm{Pb})$. Zeitschrift für Anorg. und Allg. Chemie 2004, 630 (2), 234-238. https://doi.org/10.1002/zaac.200300313. 
Inverse perovskite for infrared optics by N. Ohashi et al.

(31) Nuss, J.; Mühle, C.; Hayama, K.; Abdolazimi, V.; Takagi, H. Tilting Structures in InversePerovskites, $M_{3} T t \mathrm{O}(M=\mathrm{Ca}, \mathrm{Sr}, \mathrm{Ba}, \mathrm{Eu} ; \mathrm{Tt}=\mathrm{Si}, \mathrm{Ge}, \mathrm{Sn}, \mathrm{Pb})$. Acta Crystallogr. Sect. $B$ Struct. Sci. Cryst. Eng. Mater. 2015, 71 (3), 300-312. https://doi.org/10.1107/S2052520615006150.

(32) Kresse, G.; Hafner, J. Ab Initio Molecular-Dynamics Simulation of the Liquid-Metal-AmorphousSemiconductor Transition in Germanium. Phys. Rev. B 1994, 49 (20), 14251-14269. https://doi.org/10.1103/PhysRevB.49.14251.

(33) Kresse, G.; Furthmüller, J. Efficiency of Ab-Initio Total Energy Calculations for Metals and Semiconductors Using a Plane-Wave Basis Set. Comput. Mater. Sci. 1996, 6 (1), 15-50. https://doi.org/10.1016/09270256(96)00008-0.

(34) Blöchl, P. E. Projector Augmented-Wave Method. Phys. Rev. B 1994, 50 (24), 17953-17979. https://doi.org/10.1103/PhysRevB.50.17953.

(35) Kresse, G.; Joubert, D. From Ultras oft Ps eudopotentials to theProjector Augmented-Wave Method. Phys. Rev. B 1999, 59 (3), 1758-1775. https://doi.org/10.1103/PhysRevB.59.1758.

(36) Perdew, J. P.; Burke, K.; Ernzerhof, M. Generalized Gradient Approximation Made Simple. Phys. Rev. Lett. 1996, 77 (18), 3865-3868. https://doi.org/10.1103/PhysRevLett.77.3865.

(37) Perdew, J. P.; Ruzsinszky, A.; Csonka, G. I.; Vydrov, O. A.; Scuseria, G. E.; Constantin,L. A.; Zhou, X.; Burke, K. Restoring theDensity-Gradient Expansion for Exchange in Solids and Surfaces. Phys. Rev. Lett. 2008, 100 (13), 136406. https://doi.org/10.1103/PhysRevLett.100.136406.

(38) Perdew, J. P.; Ernzerhof, M.; Burke, K. Rationale for Mixing Exact Exchange with Density Functional Approximations. J. Chem. Phys. 1996, 105 (22), 9982-9985. https://doi.org/10.1063/1.472933.

(39) Adamo, C.; Barone, V. Toward Reliable Density Functional Methods without Adjustable Parameters: The PBE0 Model. J. Chem. Phys. 1999, 110(13), 6158-6170. https://doi.org/10.1063/1.478522.

(40) International Tables for Crystallography; Hahn, T., Ed.; International Tables for Cry stallography; International Union of Cry stallography: Chester, England, 2006; Vol. A. https://doi.org/10.1107/97809553602060000100.

(41) Monkhorst, H. J.; Pack, J. D. Special Points for Brillouin-Zone Integrations. Phys. Rev. B 1976, 13 (12), 5188-5192. https://doi.org/10.1103/PhysRevB.13.5188. 
Inverse perovskite for infrared optics by N. Ohashi et al.

(42) Pack, J. D.; Monkhorst, H. J. “Special Points for Brillouin-Zone Integrations”—a Reply. Phys. Rev. B 1977, 16 (4), 1748-1749. https://doi.org/10.1103/PhysRevB.16.1748.

(43) M Ganose, A.; J Jacks on, A.; O Scanlon, D. Sumo: Command-Line Tools for Plotting and Analysis of Periodic Ab Initio Calculations. J. Open Source Softw. 2018, 3 (28), 717. https://doi.org/10.21105/joss.00717.

(44) Kutzelnigg, W. Atoms in Molecules. A QuantumTheory. (Reihe:InternationalSeries of Monographs on Chemistry, Vol. 22.) Von R.F.W. Bader. Clarendon Press, Oxford, 1990. XVIII, 438 S., Geb. £ 50.00. ISBN 0-19-855168-1. Angew. Chemie 1992, 104 (10), 1423-1423. https://doi.org/10.1002/ange.19921041040.

(45) Ud Din, H.; Reshak, A.H.; Murtaza, G.; Amin, B.; Ali, R.; Alahmed, Z. A.; Chyský, J.; Bila, J.; Kamarudin, H. Structural, Elastic, Thermal and Electronic Properties of $\mathrm{M}_{2} \mathrm{X}(\mathrm{M}=\mathrm{Sr}, \mathrm{Ba}$ and $\mathrm{X}=\mathrm{Si}, \mathrm{Ge}, \mathrm{Sn})$ Compounds in Anti-Fluorite Structure: First Principle Calculations. Indian J. Phys. 2015, 89 (4), 369-375. https://doi.org/10.1007/s 12648-014-0585-4.

(46) Lebègue, S.; Arnaud, B.; Alouani, M. Calculated Quasiparticle and Optical Properties of Orthorhombic and Cubic $\mathrm{Ca}_{2}$ Si. Phys. Rev. B 2005, 72 (8), 085103. https://doi.org/10.1103/PhysRevB.72.085103.

(47) Migas, D. B.; Miglio, L.; Shaposhnikov, V. L.; Borisenko, V. E. Comparative Study of Structural, Electronic and Optical Properties of $\mathrm{Ca}_{2}$ Si. Phys. Rev. B 2003, 67 (20), 205203. https://doi.org/10.1103/PhysRevB.67.205203.

(48) Migas, D. B.; Bogorodz, V. O.; Filonov, A. B.; Shaposhnikov, V.L.; Borisenko, V. E.; Galkin, N. G. Electronic Properties of Semiconducting $\mathrm{Ca}_{2} \mathrm{Si}$ Silicide: From Bulk to Nanostructures by Means of First Principles Calculations. Jpn. J. Appl. Phys. 2015, 54 (7S2), 07JA03. https://doi.org/10.7567/JJAP.54.07JA03.

(49) Shannon, R. D.; Prewitt, C. T. Effective Ionic Radii in Oxides and Fluorides. Acta Crystallogr. Sect. B Struct. Crystallogr. Cryst. Chem. 1969, 25 (5), 925-946. https://doi.org/10.1107/S0567740869003220.

(50) Shannon, R. D.; Prewitt, C. T. Revised Values of Effective Ionic Radii. Acta Crystallogr. Sect. B Struct. Crystallogr. Cryst. Chem. 1970, 26 (7), 1046-1048. https://doi.org/10.1107/s0567740870003576. 
Inverse perovskite for infrared optics by N. Ohashi et al.

(51) Kosa, M.; Barad, H. N.; Singh, V.; Keller, D. A.; Shimanovich, K.; Rühle, S.; Anderson, A. Y.; Zaban, A.; Major, D. T. A Combined Computational and Experimental Investigation of Mg Doped $\alpha-\mathrm{Fe}_{2} \mathrm{O}_{3}$. Phys. Chem. Chem. Phys. 2016, 18 (2), 781-791. https://doi.org/10.1039/C5CP05987A.

(52) Beck, H. P. A DFT Study on the Correlation between Topology and BaderCharges: Part III, the Development ofCharge, "Size" and Coordination in Alkali and Alkaline Earth Titanates(IV). Solid State Sci. 2015, 48, 61-71.https://doi.org/10.1016/j.solidstatesciences.2015.07.007.

Taylor, N. T.; Davies, F. H.; Hepplestone, S. P. First Principles Electronic and Elastic Properties of Fres noite $\mathrm{Ba}_{2} \mathrm{TiSi}_{2} \mathrm{O}_{8}$. Mater. Res. Express 2017, 4 (12), 125904. https://doi.org/10.1088/2053-1591/aa99e8.

Baltache, H.; Khenata, R.; Sahnoun, M.; Driz, M.; Abbar, B.; Bouhafs, B. Full Potential Calculation of Structural, Electronic and Elastic Properties of Alkaline Earth Oxides MgO, CaO and SrO. Phys. B Condens. Matter 2004, 344(1-4), 334-342. https://doi.org/10.1016/j.physb.2003.09.274.

(55) Whited, R. C.; Flaten, C. J.; Walker, W.C. Exciton Thermoreflectance of MgO and CaO. Solid State Commun. 1973, 13 (11), 1903-1905. https://doi.org/10.1016/0038-1098(73)90754-0.

(56) Yamasaki, A.; Fujiwara, T. Electronic Structure of the $M$ O Oxides $(M=\mathrm{Mg}, \mathrm{Ca}, \mathrm{Ti}, \mathrm{V})$ in the GW Approximation. Phys. Rev. B 2002, 66 (24), 245108. https://doi.org/10.1103/PhysRevB.66.245108.

(57) Kaneko, Y.; Morimoto, K.; Koda, T. Optical Properties of Alkaline-Earth Chalcogenides. II. Vacuum Ultraviolet Reflection Spectra in the Synchrotron Radiation Region of 4-40EV. J. Phys. Soc. Japan 1983, 52 (12), 4385-4396. https://doi.org/10.1143/JPSJ.52.4385.

(58) Cappellini, G.; Finocchi, F.; Bouette-Russo, S.; Noguera, C. Ground-State Properties and Excitation Energies of Cubic SrO and MgO. Comput. Mater. Sci. 2001, 20 (3-4), 401-406. https://doi.org/10.1016/S09270256(00)00201-9.

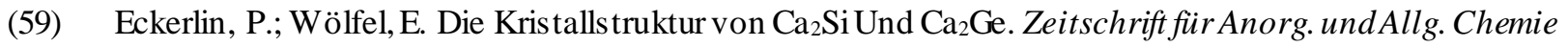
1955, 280(5-6), 321-331. https://doi.org/10.1002/zaac.19552800509.

(60) Saravanan, R.; Robert, M.C. Local Structure of the Thermoelectric Material $\mathrm{Mg}_{2} \mathrm{Si}$ Using XRD. J. Alloys Compd. 2009,479(1-2), 26-31. https://doi.org/10.1016/j.jallcom.2008.12.117.

(61) Grosch, G. H.; Range, K.-J. Studies on $\mathrm{AB}_{2}$-Type Intermetallic Compounds, I. $\mathrm{Mg}_{2} \mathrm{Ge}$ and $\mathrm{Mg}_{2} \mathrm{Sn}$ : SingleCrystal Structure Refinement and Ab Initio Calculations. J. Alloys Compd. 1996, 235 (2), 250-255. https://doi.org/10.1016/0925-8388(95)02058-6. 
Inverse perovskite for infrared optics by N. Ohashi et al.

(62) Widera, A.; Eisenmann, B.; Schäfer, H. Notizen: Darstellung Und Kristallstruktur Des $\mathrm{Sr}_{2} \mathrm{Si}$. Zeitschrift für Naturforsch. B 1976, 31 (4), 520-521. https://doi.org/10.1515/znb-1976-0424.

(63) Eisenmann, B.; Schäfer, H.; Turban, K. Neue Intermetallis che Verbindungen ImAnti-PbCl 2 Typ.Zeitschrift für Naturforsch. B 1975, 30 (9-10), 677-680. https://doi.org/10.1515/znb-1975-9-1005.

(64) Walle, A.; Ceder, G. Automating First-Principles Phase DiagramCalculations. J. Phase Equilibria 2002, 23 (4), 348-359. https://doi.org/10.1361/105497102770331596.

(65) Yin, Y;; Argent, B. The Phase Diagrams and Thermodynamics of the $\mathrm{ZrO}_{2}-\mathrm{CaO}-\mathrm{MgO}$ and $\mathrm{MgO}-\mathrm{CaO}$ Systems. J. Phase Equilibria 1993, 14 (5), 588-600. https://doi.org/10.1007/BF02669140.

(66) Jacob, K. T.; Raj, P. M.; Waseda, Y. The CaO-SrO-CuO-O ${ }_{2}$ System: Phase Equilibria and Thermodynamic Properties at 1123 K. J. Phase Equilibria 1995, 16 (2), 113-120. https://doi.org/10.1007/BF02664848.

(67) Logsdail, A. J.; Scanlon, D. O.; Catlow, C. R. A.; Sokol, A. A. Bulk Ionization Potentials and Band Alignments fromThree-Dimensional Periodic Calculations as Demonstrated on Rocksalt Oxides. Phys. Rev. B 2014, 90 (15), 155106. https://doi.org/10.1103/PhysRevB.90.155106.

(68) Logsdail, A. J.; Mora-Fonz, D.; Scanlon, D. O.; Catlow, C. R. A.; Sokol, A. A. Structural, Energetic and Electronic Properties of (100) Surfaces for Alkaline Earth Metal Oxides as Calculated with Hybrid Density Functional Theory. Surf. Sci. 2015, 642, 58-65.https://doi.org/10.1016/j.susc.2015.06.012. 
Inverse perovskite for infrared optics by N. Ohashi et al.

\section{Supporting Information}

Filename: Supporting Information_verA.1.docx

$\begin{aligned} \text { Contents } & \\ \text { S-1 } & \text { X-ray diffraction } \\ & \text { Phase identification and structural analysis } \\ \text { S-2 } & \begin{array}{l}\text { Density of states for every different compositions } \\ \text { Local DOS for R3MO compounds not displayed in the text }\end{array}\end{aligned}$


Inverse perovskite for infrared optics by N. Ohashi et al.

For Table of Contents Only

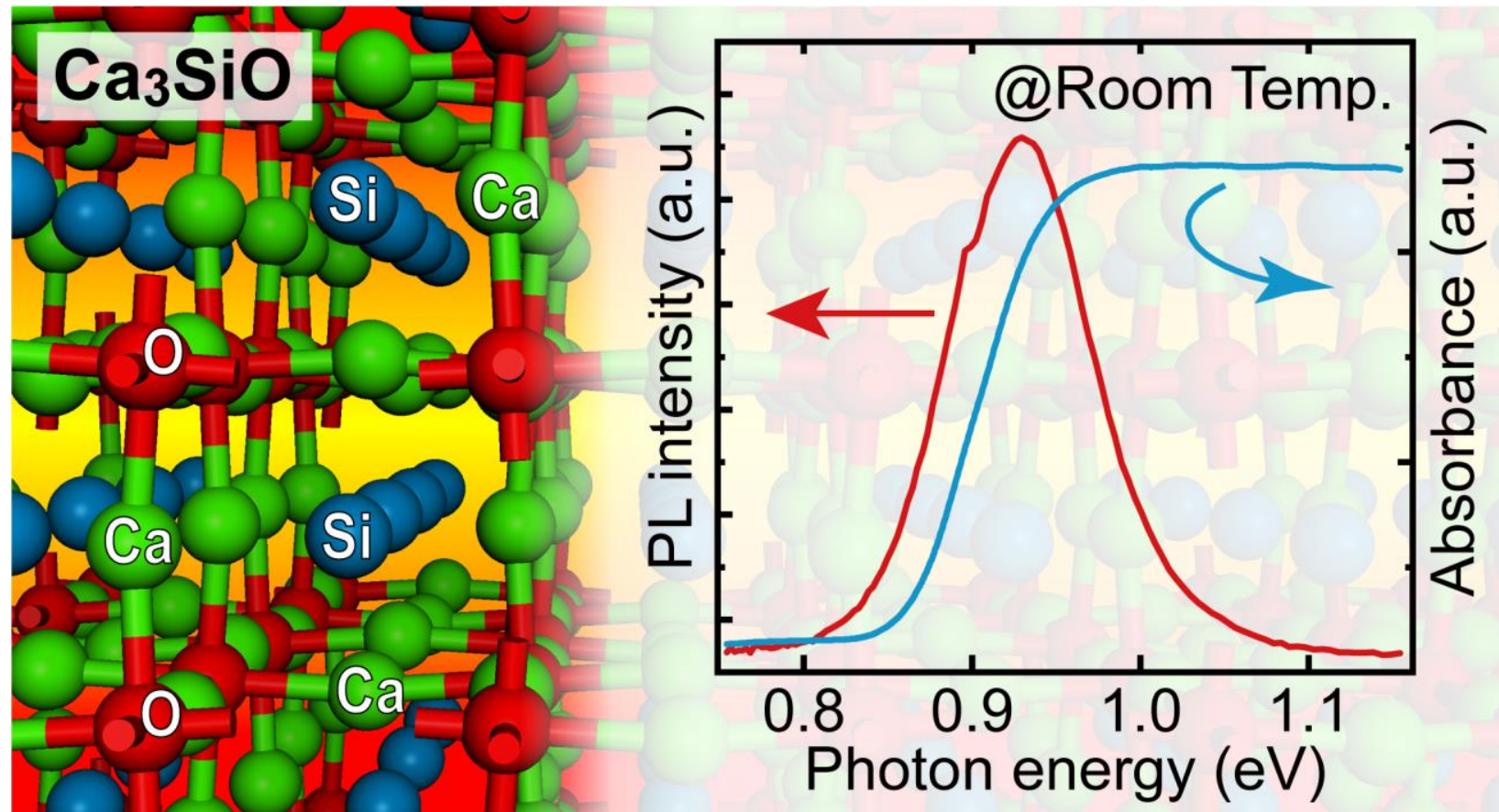

